13,03

\title{
Рентгеновская рефлектометрия и моделирование параметров эпитаксиальных пленок SiC на Si(111), выращенных методом замещения атомов
}

\author{
(C) С.А. Кукушкин ${ }^{1-3}$, К.Х. Нусупов ${ }^{4}$, А.В. Осипов ${ }^{1,3}$, Н.Б. Бейсенханов ${ }^{4}$, Д.И. Бакранова ${ }^{4}$ \\ ${ }^{1}$ Институт проблем машиноведения РАН, \\ Санкт-Петербург, Россия \\ ${ }^{2}$ Санкт-Петербургский государственный политехнический университет, \\ Санкт-Петербург, Россия \\ ${ }^{3}$ Санкт-Петербургский национальный исследовательский университет \\ информационных технологий, механики и оптики, \\ Санкт-Петербург, Россия \\ ${ }^{4}$ Казахстанско-Британский технический университет, \\ Алматы, Казахстан \\ E-mail: sergey.a.kukushkin@gmail.com \\ (Поступила в Редакцию 11 октября 2016 г.)
}

Впервые методами рентгеновской рефлектометрии, ИК-спектроскопии и атомно-силовой микроскопии, (ACM) проведено комплексное исследование структуры и состава нанослоев $\mathrm{SiC}$. Пленки $\mathrm{SiC}$ были синтезированы новым методом топохимического замещения атомов подложки при различных температурах и давлениях рабочего газа СО на поверхности высокоомного, низкодислокационного монокристаллического кремния $n$-типа ориентации (111). На основании анализа и обобщения экспериментальных данных, полученных с использованием методов рентгеновской рефлектометрии, ИК-спектроскопии и АСМ предложена структурная модель пленок $\mathrm{SiC}$ на $\mathrm{Si}$. Согласно данной модели пленки карбида кремния состоят из ряда параллельных подложке слоев, напоминающих „слоеный пирог“. Экспериментально определен состав и толщина каждого слоя, входящего в структуру пленки. Обнаружено, что во всех образцах присутствует в сверхстехиометрическом состоянии углерод, однако, его структура существенно различна для образцов, синтезированных при температурах $1250^{\circ} \mathrm{C}$ и $1330^{\circ} \mathrm{C}$, соответственно. В первом случае поверхность пленок насыщена кремниевыми вакансиями и углеродом, находящимся в структурно „рыхлой“ форме, напоминающей углерод в состоянии HOPG. В пленках, выращенных при температуре $1330^{\circ} \mathrm{C}$, углерод находится в плотной структуре, приближающейся по плотности к алмазу.

С.А. Кукушкин и А.В. Осипов благодарят за финансовую поддержку РФФИ (гранты №№ 15-0306155, 16-29-03149-офи-м). Нусупов К.Х., Бейсенханов Н.Б. и Бакранова Д.И. благодарят за финансовую поддержку Комитет науки МОН РК (гранты ГР №№ 0262/ГФ4, 4327/ГФ4; 2015-2017 гг.).

Часть экспериментальных исследований проводились при использовании оборудования Уникальной научной установки (УНУ) „Физика, химия и механика кристаллов и тонких пленок“ ФГУН ИПМаш РАН.

DOI: $10.21883 /$ FTT.2017.05.44391.379

\section{1. Введение}

Методы создания гетероструктур путем эпитаксиального роста приводят к удовлетворительным практическим результатам лишь в том случае, если постоянные решетки материала подложки и пленки отличаются не более, чем на 5\%. Различие в параметрах решеток карбида кремния $(\mathrm{SiC})$ и монокристаллического кремния $(\mathrm{Si})$ составляет $\sim 20 \%$, а разница в их термических коэффициентах расширения $~ 8 \%$ [1-3]. Именно поэтому, выращивание высокоориентированных эпитаксиальных слоев $\mathrm{SiC}$ на подложке $\mathrm{Si}$ является не тривиальной задачей.

В обзорах [2,3] были изложены основные положения нового метода синтеза тонких эпитаксиальных пленок $\mathrm{SiC}$ на $\mathrm{Si}$, предложенного теоретически и реализованного экспериментально авторами [4-6]. В его основе лежит идея топохимического замещения части атомов кремния на атомы углерода внутри кремниевой подложки. Для реализации данного подхода в межузельную позицию решетки кремния предварительно внедряют атом углерода, а соседний с ней атом кремния удаляют, создавая кремниевую вакансию. При этом в приповерхностной области решетки Si образуется ансамбль дилатационных диполей - устойчивых комплексов, состоящих из центров дилатации - атома углерода в межузельной позиции и кремниевой вакансии $\left(\mathrm{C}-V_{\mathrm{Si}}\right)$. В кристалле кубической симметрии эти два центра дилатации упруго взаимодействуют друг с другом. В частности, если дилатационные диполи расположены перпендикулярно плоскости (111) кремния, то они притягиваются друг к другу и практически вся дилатационная упругая энергия, возникшая из-за внедрения атома углерода и образования вакансии, релаксирует. Синтез упругих диполей 
осуществляется при помощи химической реакции (1)

$$
2 \mathrm{Si}_{\text {solid }}+\mathrm{CO}_{\mathrm{v}}=\mathrm{SiC}_{\text {solid }}+\mathrm{SiO}_{\mathrm{v}}
$$

протекающей между кремнием и монооксидом углерода $(\mathrm{CO})$. Скорость данной химической реакции максимальна вдоль направления, вдоль которого дилатационные диполи притягиваются, т.е. вдоль направления [111] подложки $\mathrm{Si}$. После завершения процесса химического превращения механические диполи, выполнившие свою роль, распадаются на пленку карбида кремния и поры под ее поверхностью. Ориентацию пленки при этом задает „старая“ кристаллическая структура исходной матрицы $\mathrm{Si}$, а не только поверхность подложки, как это обычно реализуется в традиционных методиках выращивания пленок. Температура и давление газа выбираются так, чтобы процесс зарождения зародышей $\mathrm{SiC}$ и пор протекал одновременно и с одинаковой скоростью. Об-

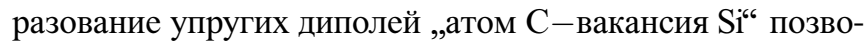
ляет получать эпитаксиальные пленки карбида кремния высокого качества.

Одним из важнейших свойств метода замещения атомов является уникальная возможность с его помощью выращивать не только кубический, но и ряд гексагональных политипов $\mathrm{SiC}$ [2,3]. Известно [7-9], что $\mathrm{SiC}$ имеет более 250 различных политипов. $\mathrm{SiC}$ существует в двух основных кристаллических модификациях - гексагональной $\alpha-\mathrm{SiC}(6 H-\mathrm{SiC}(a=0.3073 \mathrm{~nm}, c=1.511 \mathrm{~nm}$, $\left.E_{g}=3.03 \mathrm{eV}\right) ; \quad 4 H-\mathrm{SiC} \quad(a=0.3073 \mathrm{~nm}, c=1.053 \mathrm{~nm}$, $\left.\left.E_{g}=3.26 \mathrm{eV}\right)\right)$ и кубической $\beta-\mathrm{SiC} \quad(a=0.43596 \mathrm{~nm}$, $\left.E_{g}=2.36 \mathrm{eV}\right)$.

Согласно работам [2,3] в процессе синтеза $\mathrm{SiC}$ методом замещения атомов, одновременно с зарождением слоя карбида кремния, образуются усадочные поры. Их образование есть следствие различия в объемах, приходящихся на атом материала пленки $\mathrm{SiC}$ и материала подложки Si. Образование усадочных пор нежелательный процесс. В работе [2] показано, что добавлением силана $\left(\mathrm{SiH}_{4}\right)$ к основному газу $\mathrm{CO}$ можно добиться их полного залечивания. При этом поверхность $\mathrm{SiC}$ становится гладкой.

Цель данной работы - комплексное исследование методами рентгеновской рефлектометрии, ИК-спектроскопии и атомно-силовой микроскопии структуры и состава нанослоев $\mathrm{SiC}$, синтезированных на поверхности высокоомного, низкодислокационного монокристаллического кремния $n$-типа ориентации (111). Основное внимание в данной работе уделяется определению состава, плотности, толщины и шероховатости поверхности пленок методом рентгеновской рефлектометрии с использованием специально разработанного метода моделирования [10], ранее не применявшихся к исследованию пленок данного типа. Эти данные будут сопоставляться с результатами исследований, полученных с использованием методов ИК-спектроскопии и атомно-силовой микроскопии [2-6,11-16], пленок $\mathrm{SiC}$, синтезированных методом замещения атомов и пленок $\mathrm{SiC}$, выращенных методом ионной имплантации.

\section{2. Эксперимент}

Для синтеза монокристаллических пленок карбида кремния использовались две партии образцов монокристаллического кремния $n$-типа с удельным сопротивлением в пределах 1987-3165 $\Omega \cdot \mathrm{cm}$, ориентации (111), диаметром $20 \mathrm{~mm}$ и толщиной $1300 \mu \mathrm{m}$, которые были подвергнуты плоскопараллельной двухсторонней шлифовке и полировке до обретения зеркального блеска и толщины $1100 \mu \mathrm{m}$. Затем отобранные образцы № 1, 3 и 4 (все, кроме образца № 2) были подвергнуты химическому травлению в смеси кислот в соотношении $\mathrm{HF}: \mathrm{HNO}_{3}=1: 10$ до толщины $870 \mu \mathrm{m}$. Далее все образцы, включая и образец № 2, были подвергнуты травлению в щелочном растворе КОН. После этого все образцы были покрыты слоем водорода (гидрированы) с целью предотвращения образования оксида кремния по методике [17]. Затем, на поверхности этих образцов методом замещения атомов $[2,3,6]$ были выращены пленки $\mathrm{SiC}$. Синтез пленок $\mathrm{SiC}$ проводился в специальной, разработанной авторами работ $[3,6]$, установке в смеси газов $\mathrm{CO}$ и $\mathrm{SiH}_{4}$. Условия синтеза были следующими. На образцах с номерами № 1 и 2 синтез пленок $\mathrm{SiC}$ проводился при температуре $1250^{\circ} \mathrm{C}$ и давлении основного газа СО $264 \mathrm{~Pa}$. Время синтеза составило $15 \mathrm{~min}$. На образцах № 3 и 4 синтез $\mathrm{SiC}$ проводился в течение $7 \mathrm{~min}$ при температуре $1330^{\circ} \mathrm{C}$ и давлении основного газа СО $395 \mathrm{~Pa}$. Расход газа СО во время синтеза всех пленок составлял $12 \mathrm{sccm}$, а расход моносилана $\mathrm{SiH}_{4}-0.25 \mathrm{sccm}$.

Состав и структура пленок после синтеза были исследованы с использованием ИК-спектрометра Nicolet iS-50 (Thermo Scientific, USA). Программное обеспечение к Nicolet iS-50 позволяет использовать современные программы по разложению инфракрасных спектров на компоненты.

Микроструктура поверхности исследовалась на атомно-силовом микроскопе JSPM5200 Jeol Japan с использованием полуконтактного (AFM AC)-метода. Разрешение микроскопа по плоскости составляет $0.14 \mathrm{~nm}$, вертикальное разрешение $-0.01 \mathrm{~nm}$.

Плотность и толщина пленок определялись при помощи метода рентгеновской рефлектометрии. Измерения этих величин проводились путем регистрации угловой зависимости коэффициента отражения с использованием двух спектральных линий $\mathrm{Cu} K_{\alpha}(0.154 \mathrm{~nm})$ и $\mathrm{Cu} K_{\beta}$ $(0.139 \mathrm{~nm})$ на установке Complexray C6 [18]. Данные рентгеновской рефлектометрии анализировались при помощи пакета программ Release [10].

\section{3. Результаты и обсуждение}

3.1. Исследования методом ИК-спектрос ко п и и. Для определения структурного совершенства пленок были сняты ИК-спектры поглощения пленок 

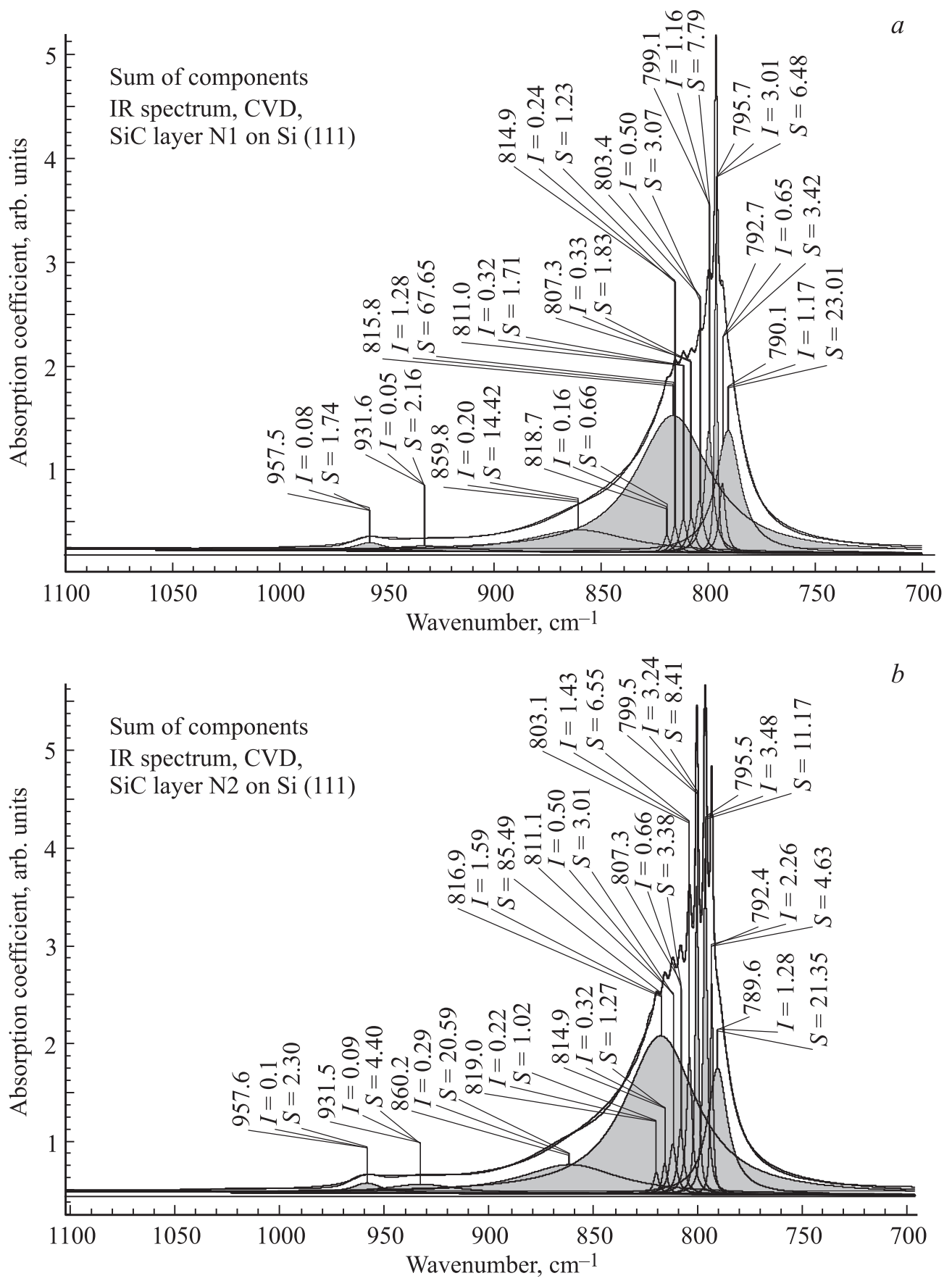

Рис. 1. Математическое разложение ИК-спектра поглощения пленок № $1(a)$ и № $2(b)$ карбида кремния, синтезированных при температуре $1250^{\circ} \mathrm{C}$ и давлении $264 \mathrm{~Pa}(S-$ площадь, $I$ - амплитуда компоненты).

$\mathrm{SiC}$ и выполнено их разложение на компоненты. Разложение спектров на составляющие дало возможность определить положение компонент в спектре, вычислить их площадь и измерить их амплитуду. Это, в свою очередь, позволило определить фазовый состав пленок. Полученные данные в ходе исследования ИК-спектров пленок приведены на рис. 1 и 2.

Из этих данных можно сделать следующие выводы. В ИК-спектре образца № 1 наблюдается интенсивный пик монокристаллической фазы карбида кремния с мак- симумом при $795.7 \mathrm{~cm}^{-1}$. Этот же пик наблюдается и в спектре образца № 3, хотя несколько меньшей интенсивности. В спектрах образцов № 2 и 4 данный пик отсутствует. Вместо этого пика в спектре образца № 2 появляется пик при $795.5 \mathrm{~cm}^{-1}$, а в спектре образца № 4 пик с частотой $796.0 \mathrm{~cm}^{-1}$. Согласно данным, приведенным в [19], теоретические величины пиков инфракрасного поглощения для кубической, гексагональной и ромбической модификаций следующие: $795.9 \mathrm{~cm}^{-1}$ для $\beta-\mathrm{SiC}(3 C-\mathrm{SiC}), 799.5 \mathrm{~cm}^{-1}$ для $2 H-\mathrm{SiC}, 797.6 \mathrm{~cm}^{-1}$ для 

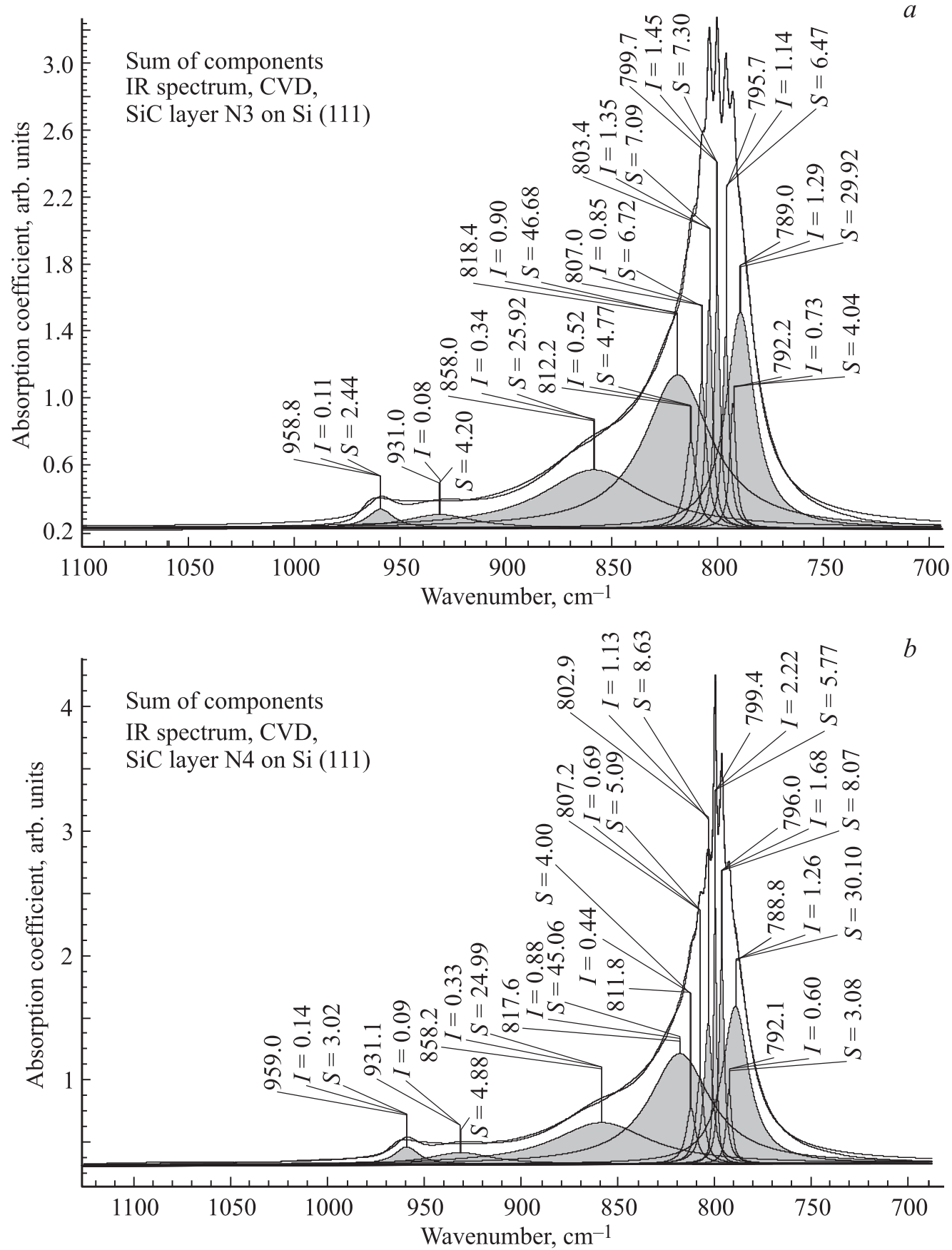

Рис. 2. Математическое разложение ИК-спектра поглощения пленок № $3(a)$ и № $4(b)$ карбида кремния, синтезированных при температуре $1330^{\circ} \mathrm{C}$ и давлении $395 \mathrm{~Pa}(S-$ площадь, $I$ - амплитуда компоненты).

$4 H-\mathrm{SiC}, 797.0 \mathrm{~cm}^{-1}$ для $6 H-\mathrm{SiC}, 797.5 \mathrm{~cm}^{-1}$ для $15 R-\mathrm{SiC}$. Таким образом, можно утверждать, что в образце № 1 в качестве основной кристаллической фазы карбида кремния присутствует монокристаллический кубический политип $3 \mathrm{C}$-SiC. Учитывая, что экспериментальные значения могут незначительно отличаться от расчетных значений [19], можно однозначно утверждать, что фаза $3 C$-SiC присутствует и в образцах № 2 и 4. Пики, соответствующие значениям $799.1 \mathrm{~cm}^{-1}$ (образец № 1), $799.5 \mathrm{~cm}^{-1}$ (образец № 2), $799.7 \mathrm{~cm}^{-1}$ (образец № 3) и $799.4 \mathrm{~cm}^{-1}$ (образец № 4) указывают на присутствие довольно редкой гексагональной фазы $2 \mathrm{H}$-SiC. Отметим, что кривые ИК-спектров, описывающих эти пики, узкие (см. рис. 1 и 2). Это однозначно свидетельствует о кристаллическом совершенстве слоев различных политипов $\mathrm{SiC}$. Таким образом, остроконечные максимумы, присутствующие в интервале частот $792.1-799.7 \mathrm{~cm}^{-1}$ согласно $[15,19]$, мы относим к Si-C-связям, характерным для кристаллического $\mathrm{SiC}$ различных и, в частности, гексагональных модификаций. 
Спектральные компоненты со значениями $790.1 \mathrm{~cm}^{-1}$ (образец № 1), $789.6 \mathrm{~cm}^{-1}$ (образец № 2), $789.0 \mathrm{~cm}^{-1}$ (образец № 3) и $788.8 \mathrm{~cm}^{-1}$ (образец № 4) мы отнесли к Si-C-связи в мелких дефектных нанокристаллах. Действительно, ранее при исследовании аморфных слоев карбида кремния, выращенных методом ионной имплантации $[11,14,15,20-22]$, положение максимума $\mathrm{SiC}-$ пика, характеризующее вид превалирующих $\mathrm{Si}-\mathrm{C}-$ связей, находилось в пределах $700-760 \mathrm{~cm}^{-1}$ и зависело от концентрации углерода. В процессе отжига $\left(900^{\circ} \mathrm{C}\right)$ пик смещается вправо до $\sim 795-800 \mathrm{~cm}^{-1}$, увеличивает свою амплитуду и сужается, указывая на превалирование $\mathrm{Si}-\mathrm{C}$-связей тетраэдрической ориентации кристаллического $\mathrm{SiC}$. Однако компоненты как крупнокристаллической, так и мелкокристаллической, и даже аморфной фазы $\mathrm{SiC}$ присутствовали и после высокотемпературного отжига. Например, в работе [22] после отжига при температуре $1200^{\circ} \mathrm{C}$ ИК-спектры были разложены в три гауссовы компоненты: компонента $A$ аморфного $\mathrm{SiC}$ с максимумом при $700 \mathrm{~cm}^{-1}$, компонента $B_{1}$ (с большей шириной в половине максимума) мелкозернистого $\beta$-SiC с максимумом при $795 \pm 1 \mathrm{~cm}^{-1}$ и компонента $B_{2}$ (с меньшей полушириной) крупнозернистого $\beta$-SiC c максимумом при $795 \pm 1 \mathrm{~cm}^{-1}$. В работе [11] было показано, что после высокотемпературного отжига при $1250-1400^{\circ} \mathrm{C}$ слоев $\mathrm{SiC}$, синтезированных имплантацией ионов углерода с энергией $10 \mathrm{keV}, 40 \mathrm{keV}$ либо многократной имплантацией ионов различных энергий, максимум SiC-пика и компоненты кристаллической фазы находились выше $793 \mathrm{~cm}^{-1}$, а максимумы компонент аморфной фазы лежали в пределах $736.2-742.6 \mathrm{~cm}^{-1}$. Исходя из этого, компоненты ИК-спектра после высокотемпературного синтеза с максимумом при 790.1, 789.6, 788.8 или $788.7 \mathrm{~cm}^{-1}$ мы отождествили с дефектной нанокристаллической фазой $\mathrm{SiC}$.

Как можно видеть на рис. 1 и 2, ситуация существенным образом становится зависящей от температуры синтеза пленки и предварительной обработки подложки кремния. Так, у образца № 1 наблюдается ряд узких пиков с частотами 803.4, 807.3, 811.0, 814.9, $818.7 \mathrm{~cm}^{-1}$, которые могут отражать поглощение мелкими нанокристаллами. Действительно, авторы работы [19], анализируя работы по изучению эмиссии малых частиц $\mathrm{SiC}$ диаметром $0.3-3 \mu$ в космических объектах, отмечают, что широкий пик в области $11.3 \mu\left(\sim 885 \mathrm{~cm}^{-1}\right)$ был интерпретирован различными авторами как эмиссия малых частиц $\mathrm{SiC}$ между частотами поперечных $\left(\sim 795 \mathrm{~cm}^{-1}\right)$ и продольных $\left(\sim 960 \mathrm{~cm}^{-1}\right)$ оптических фононов. Авторами наблюдались пики вплоть до $11.9 \mu$ $\left(\sim 840 \mathrm{~cm}^{-1}\right)$ и были отмечены такие трудности при интерпретации ИК-спектров как экстремальная чувствительность профиля пика $\mathrm{SiC}$ к влиянию размеров и формы частиц, появление многих различных кристаллических политипов $\mathrm{SiC}$ и возможность влияния неупорядоченных структур. В связи с этим, вышеуказанные остроконечные пики в интервале $803-819 \mathrm{~cm}^{-1}$ могут указывать на их принадлежность к группам мелких нанокристаллов $\mathrm{SiC}$, отличающихся размерами. Помимо этого, присутствует также широкий гауссов пик с максимумом при частоте $815.8 \mathrm{~cm}^{-1}$, который в соответствии с выводами работ $[11,15,19]$ можно отнести к Si-С-связям на поверхности мелких нанокристаллов $\mathrm{SiC}$ широкого спектра размеров с превалированием нанокристаллов, поглощающих при $815.8 \mathrm{~cm}^{-1}$. Эти нанокристаллы могут располагаться как на границе раздела „пленка $\mathrm{SiC}-$ подложка“, так и внутри кремниевой подложки, покрывая внутреннюю поверхность пор. Первые нанокристаллы $\mathrm{SiC}$ назовем нанокристаллами первого типа, а нанокристаллы, формирующиеся вместе с порами при проникновении молекул СО, нанокристаллами второго типа. Структура этих нанокристаллов в общем случае может быть различной.

Образец № 2 демонстрирует подобную структуру с небольшим сдвигом максимумов частот либо влево, либо вправо вдоль оси волновых чисел. У пленок № 3 и 4, выращенных при более высокой температуре подложки, часть пиков, частоты которых превышают $803 \mathrm{~cm}^{-1}$, стали более широкими и имеют большие площади, и, напротив, широкий пик при $\sim 818 \mathrm{~cm}^{-1}$ имеет существенно меньшую площадь. Это указывает на более интенсивное формирование групп нанокристаллов $\mathrm{SiC}$ различных размеров в переходной области „пленка-подложка“. Область частот, лежащую между $818-959 \mathrm{~cm}^{-1}$ можно отнести преимущественно к укороченным Si-C-связям между атомами в нанокластерах $\mathrm{SiC}[11,15]$.

Следует особо выделить пик с максимумом в области $957.5-959.0 \mathrm{~cm}^{-1}$, присутствующий во всех образцах. Особенно четко этот пик проявился в образце № 3 $\left(958.8 \mathrm{~cm}^{-1}\right)$ и образце № $4\left(959.0 \mathrm{~cm}^{-1}\right)$. Ранее, в работе [23] данная полоса была обнаружена в ИК-спектре пропускания пленок $\mathrm{SiC} / \mathrm{Si}$, выращенных методом замещения атомов. Как было показано в [23], этот пик соответствует особой механической связи энергии колебаний упругого диполя - упруго взаимодействующих атома углерода в межузельной позиции и кремниевой вакансии $\left(\mathrm{C}-V_{\mathrm{Si}}\right)$, образующейся в процессе замещения атомов $\mathrm{Si}$ на атомы С. Данный объект был впервые описан в работе [5] и назван дилатационным диполем. Образуются дилатационные диполи только при росте $\mathrm{SiC}$ на $\mathrm{Si}$ методом замещения атомов кремния на углерод в атмосфере CO.

Учитывая ранее полученные экспериментальные данные по электронографии, фотолюминесценции, высокоразрешающей микроскопии, растровой микроскопии, эллипсометрии и рамановской спектроскопии пленок $\mathrm{SiC}[2-5,12,13]$, выращенных методом замещения атомов, а также, принимая во внимание теоретический анализ механизма роста пленок $\mathrm{SiC}[2,5]$, результаты анализа ИК-спектров поглощения можно интерпретировать следующим образом. Слои $\mathrm{SiC}$, выращенные методом замещения атомов представляют собой сложную слоистую структуру $[2-5,12,13]$. На поверхности слой является монокристаллическим. Его толщина в зависимости от условий синтеза лежит в пределах $70-120 \mathrm{~nm}$. 
В зависимости от условий синтеза этот слой может состоять либо только из слоя $3 C$ - $\mathrm{SiC}$, либо представляет собой многослойный „сандвич“ с чередующимися прослойками слоев кубического и гексагональных политипов $\mathrm{SiC}$. Многослойная структура наиболее выгодна с энергетической точки зрения, поскольку в этом случае происходит дополнительная релаксация механических упругих напряжений, образующихся из-за большого различия в параметрах решеток $\mathrm{Si}$ и $\mathrm{SiC}$. В нашем случае таким гексагональным политипом является неустойчивый в обычном состоянии, но устойчивый в многослойной структуре, политип $2 \mathrm{H}$-SiC. По нашему мнению, именно подобная структура и ответственна за образование узких полос в ИК-спектре в области частот 792.1-799.7 $\mathrm{cm}^{-1}$.

Монокристаллический слой, как показано в $[2,4]$, лежит на поверхности пор, подобно мосту на сваях. Внутренняя поверхность пор покрыта текстурированным слоем $\mathrm{SiC}$ различных модификаций [2]. При дальнейшем продвижении от поверхности слоя в глубь подложки $\mathrm{Si}$, концентрация углерода уменьшается, что приводит к образованию неупорядоченных нанокластеров, содержащих связи $\mathrm{Si}-\mathrm{C}$ различной длины. По нашему мнению, именно эти кластеры и поглощают ИК-излучение в области частот $818-957 \mathrm{~cm}^{-1}$.

3.2. Исследования методом атомно-силовой микроскопии. На рис. 3 приведены изображения поверхности пленок № 1-4, полученные при помощи атомно-силового микроскопа (АСМ). Характерной особенностью морфологии поверхности всех образцов является „визуализация“ плоскостей (110), вдоль которых, согласно [2], лежат дилатационные диполи, и это хорошо видно на рис. 3. Наиболее отчетливо эти плоскости видны на поверхности образца № 3. Они проявляются и на образцах № 1 и 4. На боковых гранях в нижней части выступов на поверхности образца № 2 хорошо видно начало образования этих плоскостей. Образование подобного рода ансамбля плоскостей связано с особенностями роста $\mathrm{SiC}$ методом замещения атомов. Согласно работам [2,5] именно в этой плоскости

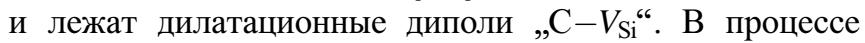
химического замещения часть атомов кремния удаляется из подложки, переходя в газообразную фазу $\mathrm{SiO}$, а часть превращается в $\mathrm{SiC}$. Поскольку объемы, приходящиеся на атом в $\mathrm{Si}$ и на молекулу в $\mathrm{SiC}$ сильно отличны друг от друга, то образуется слоистая структура, частично выходящая на поверхность и приводящая к увеличению ее шероховатости. В подобных „стопках“ слоев могут присутствовать отдельные слои различных политипов $\mathrm{SiC}$, что и показывает ИК-анализ, описанный выше. Чем выше температура синтеза и чем больше была протравлена исходная поверхность $\mathrm{Si}$, тем более четко выявляются эти плоскости [2]. Для получения более гладкой поверхности (при постоянной температуре), как показано в работе [2], необходимо повышать либо давление газа СО, либо его поток. На рис. 3, $a, b$ видно, что на поверхности образца № 1 более отчетливо, по сравнению с образцом № 2, проявились плоскости (110).
Этот экспериментальный факт объясняется тем, что поверхность образца № 1 более „перетравлена“, чем поверхность образца № 2. Если необходимо синтезировать $\mathrm{SiC}$ при температуре $1330^{\circ} \mathrm{C}$ с более гладкой поверхностью, чем поверхность образца, изображенного на рис. 3, $c$, то необходимо повысить давление газа СО. Это давление должно быть выше давления, при котором выращивался образец № 3 .

Наши измерения показали, что средние шероховатости $R_{a}$ пленок № $1-4$ были следующими: $R_{a 1}=1.58 \mathrm{~nm}$; $R_{a 2}=6.19 \mathrm{~nm} ; \quad R_{a 3}=2.95 \mathrm{~nm} ; R_{a 4}=1.77 \mathrm{~nm}$. Бо́льшая шероховатость $R_{a 2}$ пленки № 2, по сравнению с шероховатостью $R_{a 1}$ пленки № 1 , связана с тем, что исходная поверхность образца № 1 не только отполирована, как поверхность образца № 2, но и протравлена в $\mathrm{HF}: \mathrm{HNO}_{3}$. Таким образом, при дополнительном травлении средняя шероховатость уменьшается при одновременном возрастании структурной фрагментации плоскостями (1ㅣ).

3.3. Исследования методом рентгеновской рефлектометрии. Метод рентгеновской рефлектометрии основан на измерении отражательной способности рентгеновских лучей поверхностью материала вблизи угла полного внешнего отражения. При углах скольжения, меньших критического $\theta_{c}$, происходит явление полного внешнего отражения рентгеновских лучей, при котором излучение не заходит во вторую среду и практически полностью отражается на границе раздела.

Критический угол чрезвычайно мал и зависит от электронной плотности материала. Чем выше угол падающего рентгеновского пучка по отношению к критическому углу, тем глубже рентгеновские лучи проникают в материал. Для материалов, поверхность которых можно считать идеально плоской, отражательная способность резко уменьшается при углах больших критического. Если поверхность материала шероховатая, это вызывает более резкое снижение отражательной способности. Если материал с плоской поверхностью используется в качестве подложки и равномерно покрыт слоем другого материала, имеющего отличную электронную плотность, то отражения рентгеновских лучей от поверхности тонкой пленки и от границы раздела между подложкой и тонкой пленкой будут либо усиливаться, либо ослабляться, интерферируя друг с другом и образуя осцилляционный рисунок. В первом приближении, интенсивность, рассеянная образцом, пропорциональна квадрату модуля Фурье-преобразования электронной плотности. Таким образом, профиль плотности электронов можно вывести из измеренной интенсивности, а затем могут быть определены толщины слоев, их шероховатость и ряд других свойств. В частности, толщина пленки может быть определена из периодичности колебаний и информации о поверхности и границах пленок по угловой зависимости амплитуды колебаний. Метод рентгеновской рефлектометрии начал широко использоваться в последнее время для определения толщины, плотности и шероховатости как однослойных, 

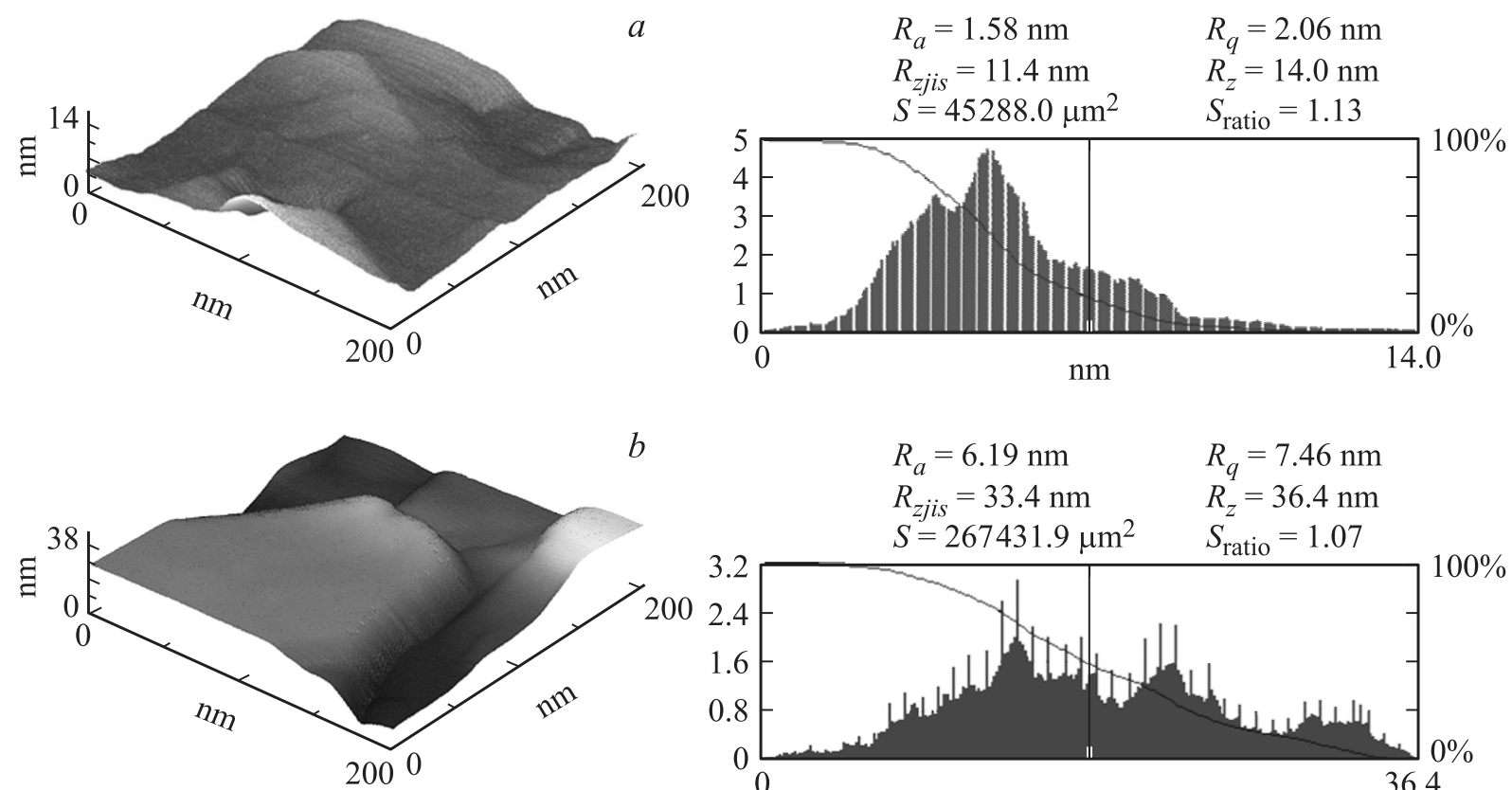

$b$
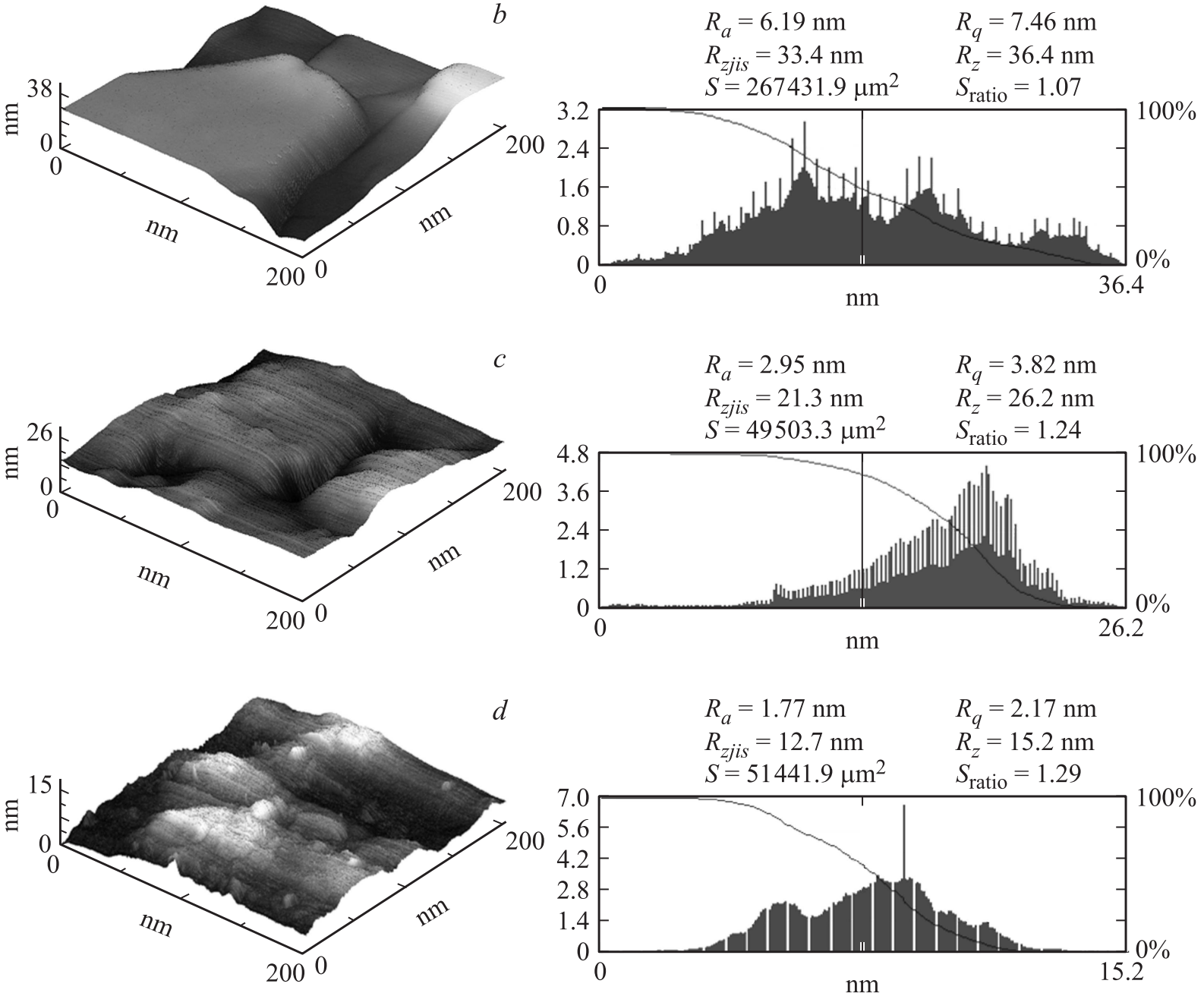

Рис. 3. Топография и шероховатость поверхностей пленок $\mathrm{SiC}$ № $1-4(a-d)$, синтезированных методом замещения атомов в кристаллической решетке кремния: $R_{a}-$ средняя шероховатость; $R_{z j i s}-$ средняя шероховатость по 10 точкам; $R_{z}-$ разность между максимумом и минимумом высоты анализируемого изображения; $R_{q}-$ корень квадратный из квадрата шероховатости; $S_{\text {ratio }}$ - площадь изображения; справа приведены гистограммы распределения высот (ось абсцисс - высота в $\mathrm{nm}$, ось ординат $k$-частота повторяемости значений высот).

так и многослойных структур. Метод рентгеновской рефлектометрии может быть с успехом использован для определения толщины и состава как кристаллических, так и аморфных материалов.

Методом рентгеновской рефлектометрии нами были измерены все образцы № 1-4. Для большей точности измерений были использованы две спектральные линии
$\mathrm{Cu} K_{\alpha}(0.154 \mathrm{~nm})$ и $\mathrm{Cu} K_{\beta}(0.139 \mathrm{~nm})$. Вследствие размытой границы раздела „пленка-подложка“ максимумы имели низкую амплитуду, что затрудняло анализ слоев $\mathrm{SiC}$. Полученные данные приведены на рис. 4-7. Для всех образцов, кроме образца № 2, были обнаружены осцилляции интенсивности, отнесенные к интерференции рентгеновских отражений в слое $\mathrm{SiC}_{x}$, где 
$x=N_{\mathrm{C}} / N_{\mathrm{Si}}$ - отношение концентрации атомов углерода к концентрации атомов кремния [11,14-16]. Если $x=1$, т.е. $\mathrm{SiC}_{x}=\mathrm{SiC}_{1}$, то это означает, что мы имеем дело со стехиометрическим карбидом кремния, т.е. на один атом углерода приходится один атом кремния. Если $x=0$, т.е. $\mathrm{SiC}_{x}=\mathrm{SiC}_{0}$, то данное вещество является чистым кремнием $\mathrm{SiC}_{0}=\mathrm{Si}$. Отметим, что при написании формульного состава пленки карбида кремния мы используем введенное Ормонтом правило [24]. Согласно этому правилу, до тех пор, пока не удается установить, является ли данное вещество однофазным или содержит
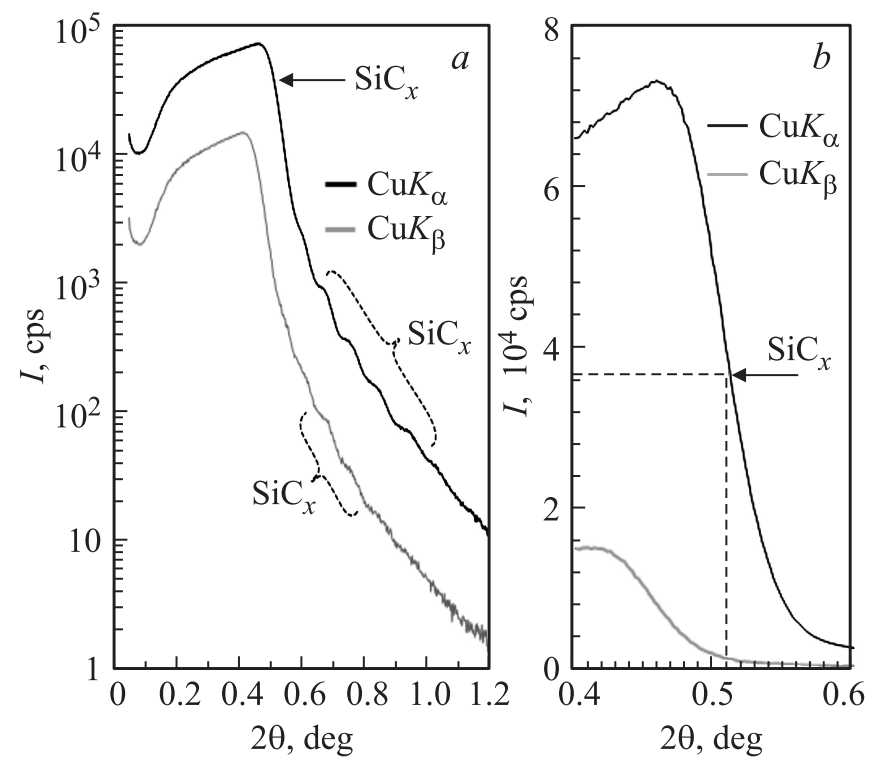

Рис. 4. Рентгеновская рефлектометрия с использованием двух спектральных линий $\mathrm{Cu} K_{\alpha}(0.154 \mathrm{~nm})$ и $\mathrm{Cu} K_{\beta}(0.139 \mathrm{~nm})$ пленки $\mathrm{Si}_{y} \mathrm{C}$ образца № 1 в логарифмическом $(a)$ и натуральном $(b)$ масштабах.
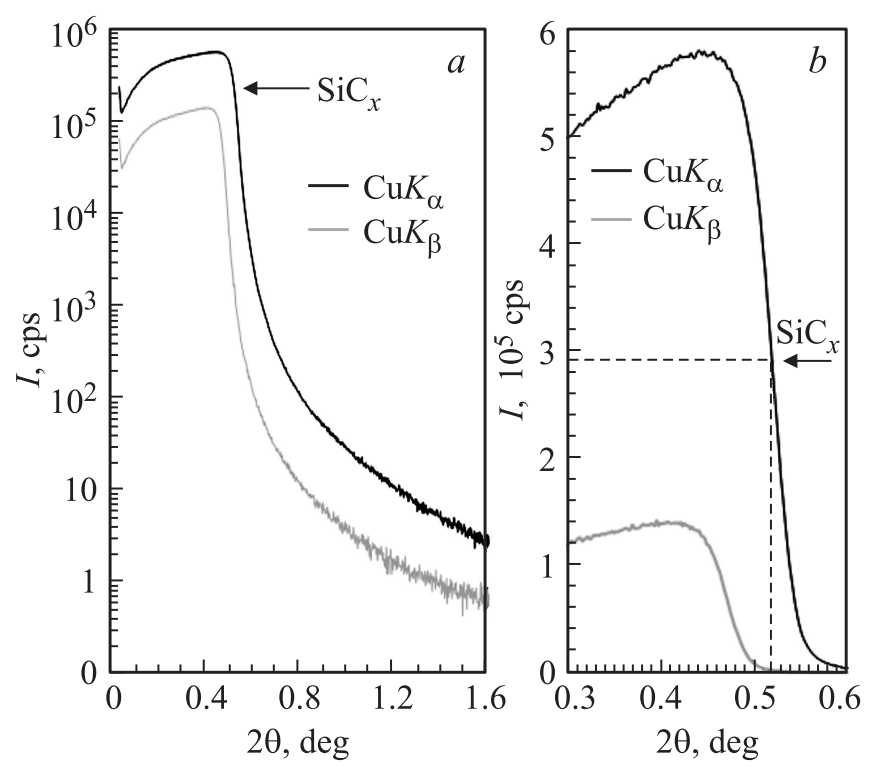

Рис. 5. Рентгеновская рефлектометрия пленки $\mathrm{Si}_{y} \mathrm{C}$ образца № 2 в логарифмическом $(a)$ и натуральном $(b)$ масштабах. две фазы, целесообразно приводить формулу вещества в виде $A B_{x}$.

Для образца № 1 основной максимум отражения на рефлектограмме с интенсивностью $I_{1}=72926$ импульсов наблюдался под углом $2 \theta=0.458^{\circ}$. Величина угла полного внешнего отражения была оценочно определена как угол, где интенсивность отражения приблизительно равна половине главного максимума $I=I_{1} / 2=36463$ импульса, то есть $2 \theta_{c}=0.511^{\circ}$ (рис. 4,b), или $\theta_{c}=0.2555^{\circ}=4.459 \mathrm{mrad}$. У образца № 2 осцилляции интенсивности, отнесенные к интерференции рентгенов-
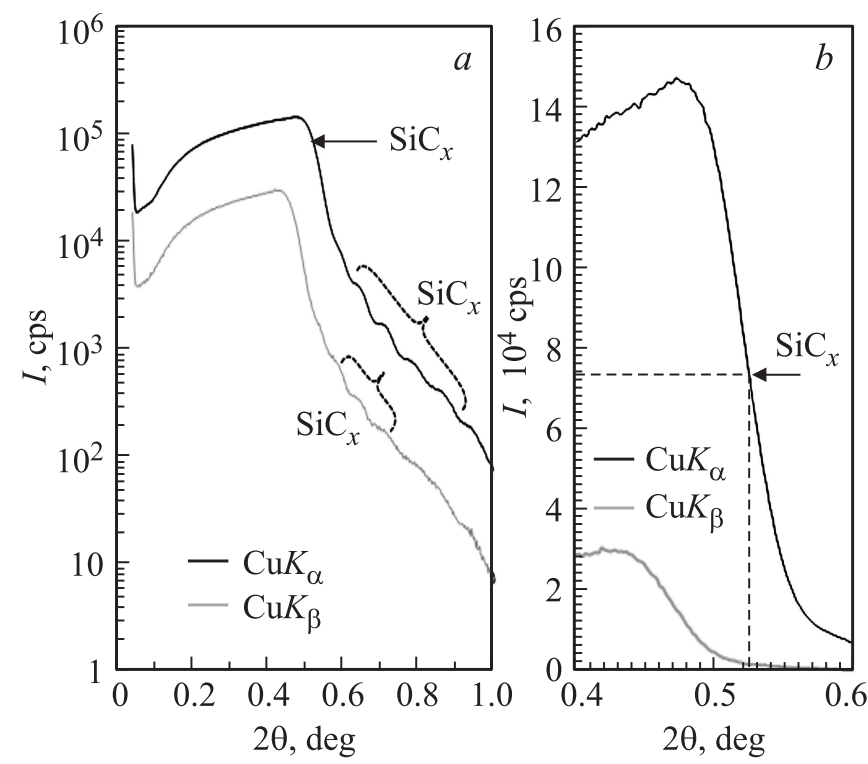

Рис. 6. Рентгеновская рефлектометрия пленки $\mathrm{Si}_{y} \mathrm{C}$ образца № 3 в логарифмическом $(a)$ и натуральном $(b)$ масштабах.
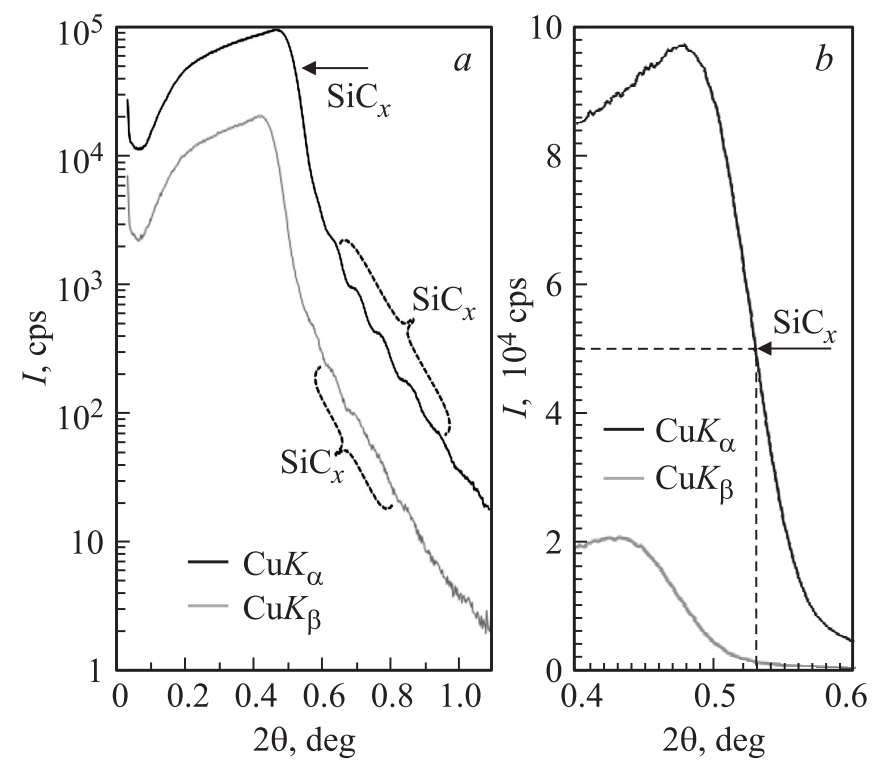

Рис. 7. Рентгеновская рефлектометрия пленки $\mathrm{Si}_{y} \mathrm{C}$ образца № 4 в логарифмическом (a) и натуральном $(b)$ масштабах. 
ских отражений в слое $\mathrm{SiC}_{x}$ (рис. 5,a) отсутствуют. Основной максимум отражения имеет интенсивность $I_{2}=581448$ импульсов. Величина угла полного внешнего отражения, соответствующая половине главного максимума $I_{2} / 2=290724$ импульса, равна $2 \theta_{c}=0.519^{\circ}$ (рис. $5, b$ ), или $\theta_{c}=0.25965^{\circ}=4.532 \mathrm{mrad}$. В образце № 3 вновь обнаруживаются осцилляции интенсивности, отнесенные к интерференции рентгеновских отражений в слое $\mathrm{SiC}_{x}$ (рис. 6,a). Основной максимум отражения имеет интенсивность $I_{3}=147030$ импульсов, которая значительно меньше, чем интенсивность $I_{2}$ отражения образца № 2. Величина угла полного внешнего отражения составила $2 \theta_{c}=0.525^{\circ}$ (рис. $6, b$ ), или $\theta_{c}=0.2625^{\circ}=4.581 \mathrm{mrad}$. На рефлектограммах образца № 4 также можно увидеть осцилляции интенсивности (рис. 7,a). Основной максимум отражения имеет интенсивность $I_{4}=97629$ импульсов, которая значительно меньше $I_{2}$ и сравнима с $I_{3}$. Величина угла полного внешнего отражения составила $2 \theta_{c}=0.529^{\circ}$ (рис. 7, $b$ ), или $\theta_{c}=0.2647^{\circ}=4.620 \mathrm{mrad}$.

Для определения химического состава, структуры слоев $\mathrm{SiC}_{x}$ и их плотности мы использовали программу Henke [25]. Эта программа позволяет по величине критического угла $\theta_{c}$ определить плотность пленки. Было получено, что величине критического угла полного внешнего отражения $4.459 \mathrm{mrad}$ для пленки $\mathrm{SiC}_{x}$ образца № 1 соответствует значение плотности $3.069 \mathrm{~g} / \mathrm{cm}^{3}$. Измеренная плотность слоя $\mathrm{SiC}_{x}$ в образце № 2 составила $3.17 \mathrm{~g} / \mathrm{cm}^{3}$, в образце № $3-3.233 \mathrm{~g} / \mathrm{cm}^{3}$, и $3.29 \mathrm{~g} / \mathrm{cm}^{3}$ в образце № 4.

На основании этих данных определим состав слоя $\mathrm{SiC}_{x}$. Для этого поступим следующим образом. Сложность анализа данной системы заключается в том, что необходимо определить, является ли данное соединение однофазным или оно состоит из двух фаз [24]. Выше мы отмечали, что процесс замещения атомов $\mathrm{Si}$ на $\mathrm{C}$ в подложке кремния проходит в несколько стадий $[2-5,26]$, в процессе которых образуются промежуточные фазы, содержащие кремниевую вакансию и углеродный атом в межузельном пространстве $\mathrm{Si}$. Подобные фазы имеют менее плотную, чем у $\mathrm{SiC}$ кристаллическую решетку. Более того, измерения остаточных упругих напряжений в пленках, выполненных ранее [2,13] на образцах подобных данным, показывают, что пленки могут быть как упруго сжаты, так и растянуты. Это зависит как от подготовки подложки $\mathrm{Si}$ к синтезу, так и от условий роста. В связи с этим, определение состава слоев по измерению плотности может привести к неоднозначным или даже неверным результатам. Поэтому, для более точного определения состава слоев $\mathrm{SiC}$ мы привлекли метод эллипсометрии и использовали при анализе эллипсометрических спектров эллипсометрическую модель, разработанную ранее в работах $[2,13,26]$ специально для анализа пленок $\mathrm{SiC}$. Конкретный вид эллипсограмм в данной работе мы не приводим, поскольку для подобной системы эллипсограммы были многократно опубликованы $[2,13,26]$. Из эллипсограмм снятых с пленок образцов № 1-4 следует, что имеются различия в параметрах и структуре пленок $\mathrm{SiC}$ образцов № 1-4. Так, согласно эллипсометрическим спектрам, толщины слоев $\mathrm{SiC}$ на образцах № 1-4 примерно составляют: № $1-99.5 \mathrm{~nm}$, № $2-99.5 \mathrm{~nm}$, № $3-110 \mathrm{~nm}$, № $4-117 \mathrm{~nm}$. Расчеты, проведенные с использованием эллипсометрической модели $[2,13,26]$, показали, что в образце № 1 содержится около 8\% вакансий $\mathrm{Si}$, № 2 - 5\% вакансий $\mathrm{Si}$, в образцах № 3 и $4-6.5 \%$ вакансий $\mathrm{Si}$. Кроме того, образец № 4 содержит в объеме $\mathrm{Si}$ под слоем пленки около 50\% пор от объема самой пленки.

Эти данные и данные, полученные нами на основании анализа ИК-спектров, позволяют предположить, что низкое значение плотности образца № 1 связано с высокой концентрацией кремниевых вакансий. Это означает, вопервых, что образец имеет несколько меньшую плотность чем стехиометрический, находящийся в идеальных условиях $\mathrm{SiC}$, во-вторых, что в данном образце в качестве второй фазы может присутствовать углерод. Отметим, что фаза монокристаллического углерода HOPG была впервые обнаружена в работе [13], а недавно наличие углерода в особом кристаллическом состоянии было подтверждено в работе [27], в которой методом синхротронного излучения в диапазоне энергий фотонов $120-450 \mathrm{eV}$ была исследована электронная структура наноинтерфейса $\mathrm{SiC} / \mathrm{Si}$. Таким образом, в случае синтеза пленки $\mathrm{SiC}$ методом замещения атомов, содержащей в избытке вакансии $\mathrm{Si}$, следует вместо формулы $\mathrm{SiC}_{x}$, в которой переменной величиной является содержание углерода, записать формулу в виде $\mathrm{Si}_{y} \mathrm{C}$, где $y=N_{\mathrm{Si}} / N_{\mathrm{C}}$, в которой переменной величиной является содержание кремния.

Как известно [11], состав слоев $\mathrm{Si}_{y} \mathrm{C}$ можно приближенно определить исходя из простой пропорции вида

$$
\frac{y-y_{1}}{\rho_{y}-\rho_{1}}=\frac{y_{2}-y_{1}}{\rho_{2}-\rho_{1}}
$$

в которой $\rho_{2}=3.21 \mathrm{~g} / \mathrm{cm}^{3}-$ плотность стехиометрического ненапряженного слоя $\mathrm{SiC}, y_{1}=0, y_{2}=1$, $\rho_{y}=3.069 \mathrm{~g} / \mathrm{cm}^{3}$, а $\rho_{1}=2.23 \mathrm{~g} / \mathrm{cm}^{3}$ плотность графита (углерода, в различных, кроме алмаза состояниях). Отсюда $y=0.86$, т.е. на 100 атомов углерода приходится 86 атомов кремния и $\mathrm{Si}_{y} \mathrm{C}=\mathrm{Si}_{0.86} \mathrm{C}$. Перепишем химическую формулу $\mathrm{Si}_{0.86} \mathrm{C}$ через процентные соотношения между атомами $\mathrm{Si}$ и $\mathrm{C}$, т.е. обозначим состав нашей пленки следующим образом $\mathrm{Si}_{z} \mathrm{C}_{1-z}$. Коэффициенты у и $z$ взаимосвязаны выражением $\mathrm{Si}_{y} \mathrm{C}_{1}=\mathrm{Si}_{1-z} \mathrm{C}_{z}$. Отсюда $y / 1=(1-z) / z \rightarrow 1-z=y z, \rightarrow 1=z(1+y) \rightarrow z=$ $=1 /(1+y)$. Тогда $\mathrm{Si}_{y} \mathrm{C}=\mathrm{Si}_{1-z} \mathrm{C}_{z}=\mathrm{Si}_{1-1 /(1+y)} \mathrm{C}_{1 /(1+y)}$, и

$$
\mathrm{Si}_{y} \mathrm{C}=\mathrm{Si}_{y /(1+y)} \mathrm{C}_{1 /(1+y)} .
$$

Отсюда имеем, $\mathrm{Si}_{0.86} \mathrm{C}=\mathrm{Si}_{0.46} \mathrm{C}_{0.54}$, т.е. содержание атомов кремния и углерода в образце № 1 составляет 46 и $54 \%$ соответственно. Отметим, что если бы были не известны данные ИК-спектроскопии, эллипсометрии 

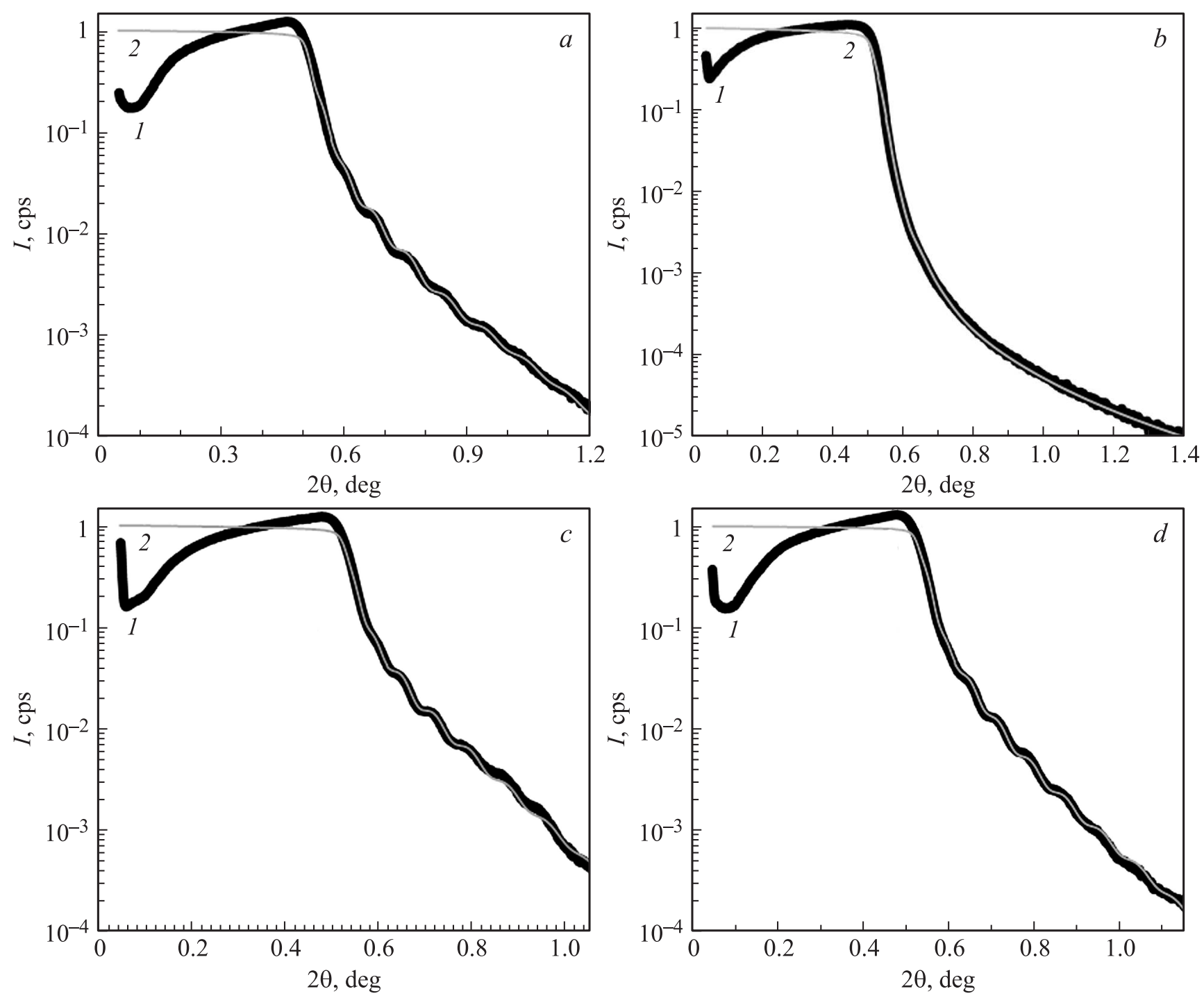

Рис. 8. Моделирование с помощью программы Release данных рентгеновской рефлектометрии по определению параметров многослойной системы $\mathrm{Si}_{y}$ С для образцов № $1(a)$, № $2(b)$, № $3(c)$, № $4(d): 1$ - экспериментальная кривая, 2 - теоретическая кривая.

и результаты, полученные в $[2,13,27]$, то результат мог бы быть противоположным, поскольку, исходя из формулы $\mathrm{SiC}$ за граничную точку отсчета $\rho_{1}$, с полным правом, мы могли выбрать плотность чистого кремния $\rho_{1}=2.33 \mathrm{~g} / \mathrm{cm}^{3}$. Это было бы верно в случае сплошных слоев $\mathrm{SiC}_{x}$, синтезированных методом ионной имплантации, как было показано в [11]. В противоположность этому, в случае слоев $\mathrm{Si}_{y} \mathrm{C}$, синтезированных методом замещения атомов и содержащих вакансии кремния, это привело бы к неверному результату, что слой содержит избыток кремния. Отметим, что в данном случае к неоднозначности приводят близкие значения плотностей кремния и углерода, не позволяющие, используя только метод рефлектомерии, сделать однозначный вывод о составе слоя.

Для пленки $\mathrm{Si}_{y} \mathrm{C}$ с плотностью $\rho_{x}=3.17 \mathrm{~g} / \mathrm{cm}^{3}$ образца № 2 , используя аналогичные рассуждения, получаем следующий состав $\mathrm{Si}_{0.96} \mathrm{C}=\mathrm{Si}_{0.49} \mathrm{C}_{0.51}$, т.е. содержание атомов кремния и углерода в пленке $\mathrm{Si}_{y} \mathrm{C}$ образца № 2 составляет 49\% атомов $\mathrm{Si}$ и $51 \%$ атомов C, соответственно, что очень близко к стехиометрическому составу.

Для пленок образцов № 3 и 4 ситуация несколько меняется. Плотности этих пленок выше, чем плотность стехиометрического $\mathrm{SiC}$ и предполагает присутствие более плотных структур, например, углерода в состоянии алмаза $\left(3.51 \mathrm{~g} / \mathrm{cm}^{3}\right)$. В этом случае анализ дает однозначные результаты, поскольку граничные фазы ( $\mathrm{SiC}$ и алмаз) не включают в себя кремний или графит и существенно отличаются по плотности. Состав слоя записывается в виде $\mathrm{Si}_{y} \mathrm{C}$, где $\mathrm{Si}_{1} \mathrm{C}$ соответствует карбиду кремния стехиометрического состава, а $\mathrm{Si}_{0} \mathrm{C}=\mathrm{C}-$ алмазу. Из пропорции, аналогичной (2), для образца № 3 получена величина $y=0.923$ и $x=1 / y=1.083$ и состав 


\begin{tabular}{|c|c|}
\hline$a$ & $b$ \\
\hline layer 1: $\mathrm{SiC}+\mathrm{Si}_{\mathrm{vac}}\left(1.58 \mathrm{~nm}, 7.0 \mathrm{~nm}, 0.5 \mathrm{~g} / \mathrm{cm}^{3}\right)$ & layer 1: $\mathrm{SiC}+\mathrm{Si}_{\mathrm{vac}}\left(6.19 \mathrm{~nm}, 3.0 \mathrm{~nm}, 2.91 \mathrm{~g} / \mathrm{cm}^{3}\right)$ \\
\hline layer 2: $\mathrm{Si}_{0.86} \mathrm{C}\left(1.05 \mathrm{~nm}, 25 \mathrm{~nm}, 3.07 \mathrm{~g} / \mathrm{cm}^{3}\right)$ & layer 2: $\mathrm{Si}_{0.96} \mathrm{C}\left(0 \mathrm{~nm}, 25 \mathrm{~nm}, 3.17 \mathrm{~g} / \mathrm{cm}^{3}\right)$ \\
\hline layer 3: $\mathrm{Si}_{0.77} \mathrm{C}\left(2.0 \mathrm{~nm}, 30 \mathrm{~nm}, 2.98 \mathrm{~g} / \mathrm{cm}^{3}\right)$ & layer 3: $\mathrm{Si}_{0.69} \mathrm{C}\left(4.0 \mathrm{~nm}, 30 \mathrm{~nm}, 2.91 \mathrm{~g} / \mathrm{cm}^{3}\right)$ \\
\hline layer 4: $\mathrm{Si}_{0.74} \mathrm{C}\left(2.0 \mathrm{~nm}, 7.5 \mathrm{~nm}, 2.95 \mathrm{~g} / \mathrm{cm}^{3}\right)$ & layer 4: $\mathrm{Si}_{0.65} \mathrm{C}\left(4.0 \mathrm{~nm}, 10.0 \mathrm{~nm}, 2.87 \mathrm{~g} / \mathrm{cm}^{3}\right)$ \\
\hline layer $5: \mathrm{Si}+$ voids $\left(9.0 \mathrm{~nm}, 14 \mathrm{~nm}, 2.1 \mathrm{~g} / \mathrm{cm}^{3}\right)$ & layer $5: \mathrm{Si}+$ voids $\left(9.0 \mathrm{~nm}, 15 \mathrm{~nm}, 2.0 \mathrm{~g} / \mathrm{cm}^{3}\right)$ \\
\hline substrate: $\mathrm{Si}\left(1.5 \mathrm{~nm}, \infty, 2.33 \mathrm{~g} / \mathrm{cm}^{3}\right)$ & substrate: $\mathrm{Si}\left(4.0 \mathrm{~nm}, \infty, 2.33 \mathrm{~g} / \mathrm{cm}^{3}\right)$ \\
\hline \multicolumn{2}{|c|}{$c$} \\
\hline layer 1: $\mathrm{SiC}+\mathrm{Si}_{\mathrm{vac}}\left(2.95 \mathrm{~nm}, 9.4 \mathrm{~nm}, 0.6 \mathrm{~g} / \mathrm{cm}^{3}\right)$ & layer $1: \mathrm{SiC}+\mathrm{Si}_{\mathrm{vac}}\left(1.77 \mathrm{~nm}, 7.3 \mathrm{~nm}, 0.4 \mathrm{~g} / \mathrm{cm}^{3}\right)$ \\
\hline layer 2: $\mathrm{Si}_{0.92} \mathrm{C}\left(1.0 \mathrm{~nm}, 34 \mathrm{~nm}, 3.23 \mathrm{~g} / \mathrm{cm}^{3}\right)$ & layer 2: $\mathrm{Si}_{0.73} \mathrm{C}\left(1.17 \mathrm{~nm}, 30 \mathrm{~nm}, 3.29 \mathrm{~g} / \mathrm{cm}^{3}\right)$ \\
\hline layer 3: $\mathrm{Si}_{0.80} \mathrm{C}\left(5.0 \mathrm{~nm}, 27 \mathrm{~nm}, 3.01 \mathrm{~g} / \mathrm{cm}^{3}\right)$ & layer 3: $\mathrm{Si}_{0.84} \mathrm{C}\left(4.0 \mathrm{~nm}, 37 \mathrm{~nm}, 3.05 \mathrm{~g} / \mathrm{cm}^{3}\right)$ \\
\hline layer 4: $\mathrm{Si}_{0.63} \mathrm{C}\left(4.0 \mathrm{~nm}, 10.0 \mathrm{~nm}, 2.85 \mathrm{~g} / \mathrm{cm}^{3}\right)$ & layer 4: $\mathrm{Si}_{0.69} \mathrm{C}\left(4.0 \mathrm{~nm}, 6.0 \mathrm{~nm}, 2.91 \mathrm{~g} / \mathrm{cm}^{3}\right)$ \\
\hline layer 5: $\mathrm{Si}+$ voids $\left(9.5 \mathrm{~nm}, 15 \mathrm{~nm}, 2.0 \mathrm{~g} / \mathrm{cm}^{3}\right)$ & layer $5: \mathrm{Si}+$ voids $\left(9.0 \mathrm{~nm}, 14 \mathrm{~nm}, 2.11 \mathrm{~g} / \mathrm{cm}^{3}\right)$ \\
\hline substrate: $\mathrm{Si}\left(1.6 \mathrm{~nm}, \infty, 2.33 \mathrm{~g} / \mathrm{cm}^{3}\right)$ & substrate: $\mathrm{Si}\left(1.4 \mathrm{~nm}, \infty, 2.33 \mathrm{~g} / \mathrm{cm}^{3}\right)$ \\
\hline
\end{tabular}

Рис. 9. Модель многослойной структуры образцов № 1-4, рассчитанная на основании экспериментальных данных при помощи программы Release $[10]$; в скобках для каждого слоя приведены значения шероховатости поверхности слоя (nm), его толщины (nm) и плотности $\left(\mathrm{g} / \mathrm{cm}^{3}\right)$.

пленки $\mathrm{Si}_{y} \mathrm{C}=\mathrm{Si}_{0.923} \mathrm{C}=\mathrm{SiC}_{1.083}$. Таким образом, на 100 атомов С приходится 92 атома $\mathrm{Si}$, или на 100 атомов $\mathrm{Si}$ приходится 108 атомов С, из которых 8 атомов являются избыточными и могут образовать нановключения алмаза, либо прочные углеродные кластеры, например, содержащие кратные связи и обладающие высокой плотностью, сравнимой с плотностью алмаза. О принципиальной возможности формирования углеродных структур в виде нанокластеров в случае ионной имплантации сообщали авторы $[11,15,28]$. В работе [28] часть имплантированного углерода формирует аморфные кластеры элементарного углерода с характером связей, свойственным графиту или алмазу. С учетом (3) для образца № 3 может быть записано $\mathrm{SiC}_{1.083}=\mathrm{Si}_{0.923} \mathrm{C}=\mathrm{Si}_{0.480} \mathrm{C}_{0.520}$, т.е. содержание атомов кремния и углерода составляет $48.0 \%$ и $52.0 \%$ соответственно.

Для образца № 4 подобная химическая формула будет иметь вид $\mathrm{SiC}_{1.364}=\mathrm{Si}_{0.733} \mathrm{C}=\mathrm{Si}_{0.423} \mathrm{C}_{0.577}$, т.е. содержание атомов кремния и углерода в этом образце составляет $42.3 \%$ и $57.7 \%$ соответственно. Таким образом, в данном образце, как и в образце № 3, можно ожидать присутствия включений в виде углеродных нанокластеров.

Для оценки толщины пленок мы использовали формулу $2 d \cdot \sin \theta=\lambda$, в которой $\lambda-$ длина волны излучения $\mathrm{Cu}_{\alpha} \quad(0.154 \mathrm{~nm})$ и $\mathrm{Cu} K_{\beta} \quad(0.139 \mathrm{~nm})$, а $2 \theta=(0.998-0.644) / 4=0.0885^{\circ}=1.545 \mathrm{mrad}-$ среднее расстояние между минимумами пика. При малых углах $\theta, \sin \theta \approx \theta$, поэтому $d=\lambda / 2 \theta \mathrm{nm}$.
Толщина слоя $\mathrm{Si}_{y} \mathrm{C}$ образца № 1 определялась нами методом рефлектометрии с использованием $\mathrm{Cu} K_{\alpha}$-излучения и $\mathrm{Cu} K_{\beta}$-излучения и составила около $100 \mathrm{~nm}$ (см. рис. 4). При этом толщина слоя, измеренная по 4 пикам $\mathrm{Cu} K_{\alpha}$-излучения, оказалась $\sim 99.8 \mathrm{~nm}$, а по двум пикам $\mathrm{Cu} K_{\beta}$-излучения $\sim 98.5 \mathrm{~nm}$, т.е. получено приемлемое совпадение. Отсутствие явно выраженных осцилляций интенсивности (рис. $5, a$ ) на кривой рентгеновской рефлектометрии не позволяет точно оценить толщину пленки на образце № 2. Толщина слоя $\mathrm{Si}_{y} \mathrm{C}$ образца № 3 при измерении по пикам излучения $\mathrm{Cu} K_{\alpha}$ оказалось равной $122.7 \mathrm{~nm}$, а в случае $\mathrm{Cu} K_{\beta}$ $124.6 \mathrm{~nm}$. Таким образом, толщина слоя $\mathrm{Si}_{y} \mathrm{C}$ образца № $3 \sim 124 \mathrm{~nm}$. Толщина слоя $\mathrm{Si}_{y} \mathrm{C}$ образца № 4 была оценена нами около $115 \mathrm{~nm}$.

Математическое моделирование и анализ микроскопической структуры слоев пленок проводился нами с использованием программы Release [10]. Это позволило получить модельные теоретические кривые (рис. 8) и сравнить их с экспериментальными кривыми рентгеновской рефлектометрии. На основании этих данных мы определили структуру слоев $\mathrm{SiC}$. Результаты моделирования структуры слоев $\mathrm{SiC}$ представлены на рис. 9 .

Согласно проведенному анализу и экспериментальным данным пленки $\mathrm{SiC}$ № 1-4 состоят из пяти слоев различной толщины и состава. Толщина, плотность и состав этих слоев меняются с глубиной от поверхности образца. Как следует из рис. 9, верхний слой (layer 1) у всех образцов, кроме образца № 2, имеет низкую плотность и представляет собой обогащенный углеро- 
дом и вакансиями кремния слой $\mathrm{SiC}$, через который рентгеновский луч проходит под малым скользящим углом. Отметим, что низкая средняя плотность этого слоя может быть обусловлена большим количеством ямок травления и дислокаций, которые образовались при предварительной обработке подложек $\mathrm{Si}$ этих образцов в смеси кислот $\mathrm{HF}: \mathrm{HNO}_{3}=1: 10$. Как показано в работе [2], наличие большой плотности дислокаций в исходной подложке кремния приводит к неконтролируемому зарождению $\mathrm{SiC}$ и образованию многочисленных дефектов на его поверхности. Только поверхность образца № 2, который не был предварительно обработан травящими растворами, наиболее близка по составу к $\mathrm{SiC}$. Следующий слой (layer 2) имеет наибольшую плотность и наиболее близок по составу к $\mathrm{SiC}$. В нижележащих слоях (layer 3 и 4) содержание углерода уменьшается. Уменьшается так же и плотность слоев, составляя величины ниже $3.21 \mathrm{~g} / \mathrm{cm}^{3}$, поэтому состав этих слоев определяется по той же схеме, как для пленок в образцах № 1 и 2. Плотность последнего пятого слоя (layer 5) меньше плотности Si. Этот слой, как показано в [2-4], представляет собой кремний, состоящий из пор, покрытых слоем $\mathrm{SiC}$ различных политипов и структуры. Отметим, что с увеличением температуры синтеза, увеличивается зона (layer 2) стехиометрического состава пленок. В образце № 4 более интенсивные процессы науглероживания привели к интенсивному выделению углерода в прочные нанокластеры повышенной плотности в layer 2. Это вызвало как уменьшение доли атомов кремния в слое, так и интенсивное образование карбида кремния в прилегающем к подложке слое. Это может сопровождаться интенсивным формированием пор, как подтверждается данными эллипсометрии.

Средние шероховатости поверхности выращенных пленок $\mathrm{SiC}$ образцов № 1, 3 и 4 сравнимы между собой и совпадают с данными атомно-силовой микроскопии для средней шероховатости участков размером $200 \times 200 \mathrm{~nm}$. Шероховатость поверхности пленки $\mathrm{SiC}$ для образца № 2 также совпадает с данными атомносиловой микроскопии на таком участке. Однако, она существенно больше шероховатости образцов № 1, 3 и 4. Но по остальным параметрам, а именно по составу и структуре, пленка № 2 наиболее совершенна. Она имеет состав $\mathrm{Si}_{0.49} \mathrm{C}_{0.51}$, наиболее близкий к стехиометрическому.

\section{4. Заключение}

Методами рентгеновской рефлектометрии и ИКспектроскопии на поглощение исследована структура и состав пленок карбида кремния на кремнии, выращенных за счет топохимического замещения части атомов подложки кремния на углерод при химической реакции кремниевой подложки с монооксидом углерода. Предложена модель, позволяющая по данным рефлектомерии и ИК-спектроскопии определять структуру и состав пленок карбида кремния. Показано, что пленки карбида кремния состоят из ряда параллельных подложке слоев, состав и структура которых существенно изменяется от поверхности пленки по направлению к подложке. Верхние слои являются монокристаллическими, а нижние слои, лежащие в глубине подложки, содержат преимущественно мелкозернистую нанокристаллическую фазу карбида кремния различных политипов. Обнаружено, что верхние слои пленок карбида кремния, в зависимости от условий синтеза насыщены кремниевыми вакансиями и углеродом в упорядоченном состоянии, что подтверждает теоретически предсказанное ранее существование упругого диполя - упруго взаимодействующих атома углерода в межузельной позиции и кремниевой вакансии.

\section{Список литературы}

[1] L. Calcagno, P. Musumeci, F. Roccaforte, C. Bongiorno, G. Foti. Appl. Surf. Sci. 184, 123 (2001).

[2] S.A. Kukushkin, A.V. Osipov. J. Phys. D 47, 313001 (2014).

[3] С.А. Кукушкин, А.В. Осипов, Н.А. Феоктистов. ФТТ 56, 1457 (2014).

[4] С.А. Кукушкин, А.В. Осипов. ФТТ 50, 1188 (2008).

[5] S.A. Kukushkin, A.V. Osipov. J. Appl. Phys. 113, 024909-1 (2013).

[6] S.A. Kukushkin, A.V. Osipov, N.A. Feoktistov. Patent № 2363067 (2008).

[7] G.R. Fisher, P. Barnes. Philosophical Mag. B 61, 217 (1990).

[8] J.K.N. Lindner. Appl. Phys. A 77, 27 (2003).

[9] M.J. Pelletier. Analytical applications of Raman spectroscopy. Blackwell Science, UK. (1999). 496 p.

[10] С.А. Апрелов. Многоволновая рентгеновская рефлектометрия для анализа многокомпонентных пространственноупорядоченных структур. Автореф. канд. дис. МГИЭТ, M. (2007). 28 c.

[11] К.Х. Нусупов, Н.Б. Бейсенханов, С.К. Жариков, И.К. Бейсембетов, Б.К. Кенжалиев, Т.К. Ахметов, Б.Ж. Сеитов. ФTT 56, 2231 (2014).

[12] T.S. Perova, J. Wasyluk, S.A. Kukushkin, A.V. Osipov, N.A. Feoktistov, S.A. Grudinkin. Nanoscale Res. Lett. 5, 1507 (2010).

[13] С.А. Кукушкин, А.В. Осипов. ФТП 471575 (2013).

[14] K.Kh. Nussupov, N.B. Beisenkhanov, I.V. Valitova, K.A. Mit', D.M. Mukhamedshina, E.A. Dmitrieva. J. Mater. Sci.: Mater. Electron. 19, 254 (2008).

[15] K.Kh. Nussupov, N.B. Beisenkhanov. In: Silicon carbidematerials, processing and applications in electronic devices / Ed. M. Mukherjee. Ch. 4. InTech, Croatia (2011). P. 69.

[16] K.Kh. Nussupov, V.O. Sigle, N.B. Bejsenkhanov. Nucl. Instrum. Meth. Phys. Res. B 82, 69 (1993).

[17] И.П. Калинкин, С.А. Кукушкин, А.В. Осипов. Способ обработки поверхности монокристаллической пластины кремния. Патент № 2323503 РФ. Приоритет 05.06.2006.

[18] A.G. Touryanski, A.V. Vinogradov, I.V. Pirshin. US Patent № 6041098 (2000).

[19] H. Mutschke, A.C. Andersen, D. Clément, T. Henning, G. Peiter. Astron. Astrophys 345, 187 (1999).

[20] J.A. Borders, S.T. Picraux, W. Beezhold. Appl. Phys. Lett. 18, 509 (1971). 
[21] Е.К. Баранова, К.Д. Демаков, К.В. Старинин, Л.Н. Стрельцов, И.Б. Хайбуллин. Докл. АН СССР 200, 869 (1971).

[22] D. Chen, W.Y. Cheung, S.P. Wong. Nucl. Instrum. Meth. Phys. Res. B 148, 589 (1999).

[23] С.А. Грудинкин, В.Г. Голубев, А.В. Осипов, Н.А. Феоктистов, С.А. Кукушкин. ФТТ 57, 2469 (2015).

[24] Б.Ф. Ормонт. Современное содержание стехиометрических законов. Фазы и соединения переменного состава. Нестехиометрические соединения. В сб.: Соединения переменного состава. Химия, Ленинград (1969). С. 10-63.

[25] B.L. Henke, E.M. Gullikson, J.C. Davis. In: Atomic Data and Nuclear. Data Tables 54, 2 (1993). 181 p. (http://henke.lbl.gov/optical_constants/).

[26] С.А. Кукушкин, А.В. Осипов. Письма в ЖТФ 42, 16 (2016).

[27] Г.В. Бенеманская, П.А. Дементьев, С.А. Кукушкин, М.Н. Лапушкин, А.В. Осипов, Б.В. Сеньковский. ФТП 50, 1348 (2016).

[28] А.И. Белов, А.Н. Михайлов, Д.Е. Николичев, А.В. Боряков, А.П. Сидорин, А.П. Грачев, А.В. Ершов, Д.И. Тетельбаум. ФТП 44, 1498 (2010). 